\title{
Study on Digital Processing Approaches of Publishing Resources
}

\author{
Xiaodi Xia ${ }^{1, a}$ \\ ${ }^{1}$ Jiangxi media Vocation College, Nanchang, Jiangxi, 330224 \\ a email
}

Keywords: Digital Processing, Publishing Resources, Approaches

\begin{abstract}
Digital publishing industry has become the current development of the overall trend. With the maturity of digital information processing technology, Chinese digital publishing has entered a new period of development. Digital publishing itself has a high degree of content integration, highly dependent on technology and the use of high market mechanism of the "three high" characteristics, determines the digital publishing will bring the reorganization of the publishing industry, so that publishers are not in the digital publishing trend and do nothing, but to combine the advantages of their own resources and digital publishing form of docking and ultimately find their own survival and development space.
\end{abstract}

\section{Introduction}

Publishing industry belongs to the content industry, content resources is undoubtedly publishing companies to digital publishing an important guarantee for the transition. Therefore, the content of digital resources development is more and more attention by many university publishers. With the great importance of higher education in China, teaching materials and academic research in colleges and universities are also quick to follow up, publishing resources every year a substantial increase, but for most university publishers, the development and utilization of digital content resources only stay At the level of primary or rough machining.

First, the contents of the digital resources are to simplify processing. University publishing house content resources into the publishing process, the completion of the traditional publishing links, many university press on the digital content of these resources to use only electronic documents, CDs and other methods of archiving, and storage format is different, there is no standardized management . This approach is not conducive to follow-up of the content resource call, let alone its digital development. There are some university publishers, the content of the digital development of the resources made a simple understanding that some of the content resources sold to some digital publishing operators or information platform to achieve the content of the digital resources. In fact, this is a great misunderstanding of digital publishing, but also a great waste of valuable content resources.

Second, the content lacks of scientific methods of selection. Some university publishers have no reasonable mechanism and method to choose the content resources, so they are in the process of transformation digital publishing, and they try their best to do what they do well. In fact, both the traditional publishing and digital publishing, publishing law will always play its due role, the characteristics of publishing and on-demand publishing publishers always maintain strong vitality of strong protection. Therefore, digital publishing should always according to their own characteristics and advantages of choice of content resources, in accordance with the actual needs of the reader to select content resources, mining and development.

Third, the low correlation of content resources. First of all, publishers have independent content resources, parallel to the same product level, such as electronic documents, statistics tables and various technical, engineering drawing, as well as the entire curriculum of teaching courseware, these products mostly only remain in the original Level, not the internal elements associated with the formation of the same content resources chain; followed by the publication of content resources and the lack of integration of external resources, in particular, can not be integrated with the appropriate digital technology, can not use the relevant platform to achieve content resource format conversion, And thus can not create a digital technology environment, the value of the industry. 


\section{Basic Requirements for Digital Publishing Resources}

The first is the availability of resources. Usability refers to two aspects and one is the copyright validity of resources, that is, after the digital processing of resources, the publishing unit for its right to use the copyright sense. Second, the value of the resource itself, whether it has a processing, multiple reuse values. In the era of traditional publishing, most of the publishing units obtained special publishing rights, and some even only non-exclusive publishing rights, and did not get the right to adapt and other forms of media rights, especially for digital publishing the most important right to network communication. If these legal issues can not be resolved, even if the publishing unit takes a lot of manpower, material and energy to digitize their works, they may face legal problems of operation in the digital environment and can not be used. To the end, for a certain value and the need to digitize the resources, digital resources has been formed secondary processing of resources. First of all to carry out the copyright authorization of the work, not a valid license of resources can not be secondary development.

The second is the flow ability of resources. The circulation of publishing resources also from a different point of view, one can flow of data itself, the second is the compatibility of the carrier, the third is the content of the demand. Achieve different carriers on a multi-processing purposes and first of all to solve the problem of the normative characters. The current domestic publishing units owned by the "digital resources", mostly based on the GB18030 character set, the character set of Chinese characters can not meet the demand for publishing with the word. So there are a large number of non-standard resources in the word, it does not have liquidity. In order to improve the circulation of resources, it is necessary to base on the resource structure, that is, on the basis of super-large character sets, and to achieve the existing resources with the five characters with the problem, namely: text with the word; The same code (the identity of the same type of heterogeneous code), the same code (all kinds of symbols in the symbolic system of the same). Only in the large character set, based on the solution of this "five with" the problem, the data really have liquidity.

Digital publications are transmitted in a passive manner, ie, resource storage is static in the operating environment, and propagation of reading activities can not be achieved without the user's demand for reading click actions. Therefore, the less information content, the less the circulation, to improve the liquidity of the resources, we must seriously solve the network environment in the reader's demand for dynamic acquisition and quantitative analysis of user needs, only to solve the demand description And describe the mechanism in order to truly achieve on-demand customization, on-demand production, on-demand processing, on-demand provision in order to truly improve the flow of resources and availability.

The third is the availability of resources. Because the resources in the digital environment exist in a static form, how to effectively organize the resources in order to facilitate the query and retrieval of the reader, how to gather information and content, how based on the user's cognitive rules, expand the organization and it is necessary to solve the problem of dynamic flow of static content by dynamically displaying the content by using the related information and effectively utilizing various media forms and integrated art.

The fourth is the maintainability of resources. One of the characteristics of digital publishing resources is the ability to dynamically update and maintain resources to meet and respond to the needs of different groups of users. Therefore, the ability to establish a strong, powerful information and processing power of the editorial team, continue to update and maintain resources, is to make the vitality of resources and sustainable development of the most vitality of the core issues, a resource such as Can not be updated and added, the demand will be depleted, the user will disappear, the value of the resource itself will decline or even die.

\section{Digital Development Path}

Digital archiving of content resources is a basic work, but also the follow-up to achieve the premise and guarantee digital development. For example, Southwest Jiaotong University Press in the paper 
book publishing, unified collection of various types of electronic documents and teaching resources, and arrange for the establishment and management of specialized content resources database, including "big traffic" text library, engineering subjects Schematic library, teaching audio-visual resource library. The database is to break the original book system model, according to the content of relevance, knowledge points or chart properties are classified. The basic work of the revision and reprint of the book, but also conducive to the primitive accumulation of data, but also shorten the development cycle of digital products, improve development efficiency, saving development costs.

Whether it is university textbooks or other college students have a complete theoretical system or depth of study, and thus the content of such publications is relatively large, complex, involving a wide range. In the past, the University Press, the so-called digital behavior are included in the book CD-ROM and other optical media, content, mostly courseware for teaching, audio and video data, etc., is better to put the content on the site, the reader Can be read according to the URL provided. However, these methods are very limited, can not meet the readers of the book "thin shape is not thin God" psychological expectations. With the promotion and application of two-dimensional code, University Press can be extended from the book to pick out the contents of the link to the two-dimensional code, to achieve real-time digital. For example, the East China University of Science and Technology Press in the book according to actual needs, the recording, video, pictures and other extended content embedded in two-dimensional code. When the reader to read some knowledge points, need to know more about the background, listen to (read) information, you can use the phone to scan real-time two-dimensional code to read. This instant digital approach is convenient and environmentally friendly, in the University textbook Jiaofu have better use prospects. It followed by the construction of digital platform courses. The so-called curriculum digital platform is a collection of digital teaching resources, teaching systems and network communication system is one of the network platform. Southwest Jiaotong University Press, in cooperation with all kinds of colleges and universities in the process of publishing traditional teaching materials, combined with college teachers in the classroom teaching practice and needs, and supporting the relevant characteristics of teaching materials, independent development of the "digital teaching platform. The platform based on the actual teaching and management needs to set a lot of plates. University teachers and managers can achieve the learning process management, curriculum resource management and teaching performance assessment on the platform, and students can interact with teachers through real-time platform. More importantly, the platform into the various disciplines of teaching content and simulation questions, students can target their own deficiencies to fill gaps. The development and application of this platform not only enriched the classroom teaching form, stimulated the interest of students, but also reduced the actual pressure and burden of teachers and students, but also expanded the radiation range of the paper textbooks, can be described as threefold.

The combination of production, teaching and research is an effective way to serve the society in colleges and universities, and it is also a realistic guarantee of running high - level colleges and universities. University Press, as an academic institution, should pay attention to cooperating with enterprises and scientific research institutions, so as to give full play to their advantages and form a powerful system of research, development and production integration, and reflect their own in the process of running. Content resource advantages and value. At this stage, many companies $\mathrm{R} \& \mathrm{D}$ and production of electronic products dazzling, high technology content, but a serious lack of content loading, they are also actively seeking content resources to increase the value-added products. For example, a large electronics company in Guangdong and Southwest Jiaotong University Press is actively negotiating the integration of content resources and digital products, the two sides share a common vision is: in the production of electronic products, direct pre-installed professional content resources, Electronic products to enter the market so that buyers can enjoy the appropriate content services.

\section{Conclusion}

As more and more publisher providers enter the field of digital publishing, passive wait can not 
save the lost positions, the traditional publishing house is bound to seek a break trend, the publishing groups have taken a positive attitude, establish digital publishing sector, launch the digital publishing project and have a positive trend.

\section{Acknowledgements}

Jiangxi Province Art Science Planning Project (YG2015189, YG2014255)

Jiangxi Provincial Department of Education 2015 science and technology research project (GJJ151274)

Jiangxi Provincial Intellectual Property Soft Science Research Project (ZR201610)

Pingxiang 2015 Science and Technology Support Program based on cloud computing in the central region of animation rendering service platform research and development.

\section{References}

[1] Ma Jinghua, Bu Jianli. How to manage the teaching aids in publishing houses [J]. Enterprise Technology Development. 2014 (13)

[2] Zhang Fang, Zhang Yuzhuo. Analysis on the Input Output Efficiency of Hightech Industry in Hebei Province [J]. Economic Forum. 2013 (04)

[3] Ma Jinghua, step established traditional production cost control [J]. Enterprise Technology Development. 2013 (25)

[4] Xu Junqiang. Based on the network perspective of communication behavior [J]. Education and Teaching Forum. 2012 (21)

[5] Xu Junqiang. Digital publishing-the future development of book publishing trends [J]. Enterprise Technology Development. 2012 (16) 